\title{
Longitudinal effects of change in body mass on measurements of ventilatory capacity
}

\author{
D J Chinn, J E Cotes, J W Reed
}

\begin{abstract}
Background - In several longitudinal studies changes in body mass and in forced expiratory volume in one second $\left(\mathrm{FEV}_{1}\right)$ have been found to be negatively correlated. This paper tests the hypothesis that failure to allow for the association can lead to error in the interpretation of longitudinal measurements of ventilatory capacity.
\end{abstract}

Methods - Male shipyard workers (n= 1005) were assessed on two occasions with an average interval between measurements of 6.9 years. A respiratory symptoms questionnaire, detailed anthropometric measurements, and dynamic spirometric tests were undertaken. Multiple regression analysis was used to identify variables which contributed to the changes in lung function.

Results - After allowing for age and growth in stature, a change in body mass of $1 \mathrm{~kg}$ was, on average, associated with a mean (SE) converse change in $\mathrm{FEV}_{1}$ of $17 \cdot 6$ $(2 \cdot 0) \mathrm{ml}$, and in forced vital capacity (FVC) of $21 \cdot 1(2 \cdot 5) \mathrm{ml}$. Neglect of changes in body mass (which in this context reflected changes in body fat) led to underestimation of the longitudinal decline in $F E V_{1}$ with age and failure to detect significant improvements in $\mathrm{FEV}_{1}$, both in smokers following discontinuation of smoking and in shipyard welders and caulker/burners as a consequence of leaving their employment. The estimated peak ages and associated peak levels of the indices were found to differ, depending on whether or not they were expressed at constant body mass.

Conclusions - Neglect of changes in body mass can lead to erroneous conclusions being drawn from longitudinal measurements of $\mathrm{FEV}_{1}$.

(Thorax 1996;51:699-704)

Respiration and

Exercise Laboratory,

Department of

Physiological

Sciences,

Medical School,

Newcastle upon Tyne

NE2 4HH, UK

D J Chinn

J E Cotes

J W Reed

Correspondence to:

Dr J E Cotes.

Received 21 December 1994

Returned to authors

7 March 1995

Revised version received

14 November 1995

Accepted for publication

9 February 1996 volume in one second $\left(\mathrm{FEV}_{1}\right)$ per $\mathrm{kg}$ gain in mass of, on average, $21.4 \mathrm{ml} / \mathrm{kg}, 13.9 \mathrm{ml} / \mathrm{kg}$, and $23 \mathrm{ml} / \mathrm{kg}^{1-3}$ Since the magnitude of this change is of the same order as the annual change in $\mathrm{FEV}_{1}$, this could be an important confounding influence because a change in exposure to tobacco smoke or to an occupational pollutant can be accompanied by a change in body mass. Similarly, since body mass usually increases from youth to middle age and then diminishes, ${ }^{4}$ some of the agerelated decline in lung function could be due to the associated changes in body mass. ${ }^{56}$ This paper explores these interrelationships using data obtained from longitudinal studies of shipyard workers, and attempts to answer the question "Can neglect of changes in body mass, standardised for stature, materially affect the interpretation of longitudinal measurements of $\mathrm{FEV}_{1}$ and FVC?"

\section{Methods}

SUBJECTS

The men were current or ex-employees of a shipyard on the river Wear (yard 1) and a group of shipyards on the river Tyne (referred to collectively as yard 2). At yard 1 the men were recruited in 1979 as a stratified sample of the workforce, including all present and past welders and caulker/burners aged $45-70$ years, and a sample of all other tradesmen, most of whom were electricians. Six hundred and eighty six men were identified and 607 attended the initial assessment; their mean age was 46.0 years. ${ }^{7}$ Subsequently 53 men died, 66 were lost to follow up, and 488 were reassessed. ${ }^{8}$ At yard 2 , men in two age groups were seen. The younger cohort (initial ages 17-30 years, mean $23 \cdot 1$ years) was recruited between August 1980 and September 1984 by which time 222 welders and 194 caulker/burners had been assessed; they comprised, respectively, $95 \%$ and $85 \%$ of the defined populations. Electricians identified from the works list were chosen as the control group, but volunteers from other trades were also accepted $(n=239)$. Three welders and four caulker/burners were subsequently excluded because the results were of poor technical quality or because of incomplete data or unrelated medical conditions. A clinical history of asthma led to the exclusion of a further 24 men (six welders, six caulker/burners, and 12 other tradesmen) leaving 624 men for inclusion in the study. The older cohort comprised 239 men who were apparently healthy and gave no history of asthma (mean age 41.7 years, range $23-47$ years); they were recruited for assessment of the physiological response to exercise. ${ }^{9}$ Follow up of both groups 
from yard $2(n=863)$ was undertaken between 1987 and 1991, during which time 548 men were reassessed. ${ }^{10}$ Lapses to follow up occurred in seven men who had died, 285 who had left the area and could not be retrieved, and 23 who refused.

In all, 1470 men were included in the study, of whom 60 died before reassessment. Complete information was available for 1005 men ( $71 \%$ ), of whom $73 \%$ had discontinued work in the shipyard during the average 6.9 years of follow up. The study was approved by relevant ethical committees in the Northern Region.

\section{MEASUREMENTS}

At each attendance the MRC questionnaire on respiratory symptoms (1976), with additional questions about employment and habitual leisure time activity, was completed. ${ }^{11}$ Anthropometric measurements included stature, body mass, fat free mass, and percentage fat; these quantities were measured using a Harpenden stadiometer and skin calipers ( $\mathrm{Hol}-$ tain Ltd, Croswell, Pembs, UK) and beam balance (Avery GEC Ltd, Smethwick, West Midlands, UK). The equipment was calibrated and used in the manner recommended for the International Biological Programme. ${ }^{12}$ The skinfolds were taken over the biceps and triceps muscles midway between the olecranon and acromion processes, below the angle of the scapula and just above and medial to the anterior superior iliac spine; details of the measurements are given elsewhere. ${ }^{5}$ The fat free mass and percentage fat were calculated from the body mass and the four skinfold thicknesses by the method of Durnin and Womersley. ${ }^{13}$

Dynamic spirometric tests were performed in quintuplicate while seated using a dry bellows digital spirometer (McDermott, Garw Electronic Instruments Ltd, Llantrisant, Glamorgan, UK); the volume/time information was encoded in real time on cassette tape as the number of $10 \mathrm{ml}$ increments of volume expired every $10 \mathrm{~ms} .{ }^{14}$ After each blow the flowvolume curve was plotted and the $\mathrm{FEV}_{1}$ and forced vital capacity (FVC) were calculated by the microprocessor on the spirometer and recorded. The highest of the first three technically satisfactory blows was accepted for analysis. The selection criteria were that the FVC was within $5 \%$ of the maximum, the flowvolume curves were of similar overall shape, and that the peak expiratory flow was within $10 \%$ of the maximal observed value. ${ }^{6}$

For the microprocessor calculation of $\mathrm{FEV}_{1}$ the expiration was considered to have started when $0 \cdot 1$ litres had been expired. Subsequently, the tape records were reprocessed using a portable computer and the start of forced expiration was redefined by back extrapolation to zero time of the steepest part of the volume-time curve.

\section{ANALYSIS OF DATA}

Multiple regression analyses were performed using the statistical package for the Social Sciences of the University of Michigan (SPSS, release $4 \cdot 0)$. Body mass $(B M)$ and fat free mass
(FFM) were expressed as body mass index $\left(\mathrm{BMI}=\mathrm{BM} \times \mathrm{St}^{-2}\right)$ and fat free mass index $\left(\mathrm{FFMI}=\mathrm{FFM} \times \mathrm{St}^{-2}\right.$ ) because, in this form, they were independent of stature (St). Multiplicative interaction terms were included if significant in the presence of their constituent variables. Shipyard trade was a categorical variable where 1 identified a man as having been a welder or caulker/burner (WCB), and 0 an electrician or other tradesman. The former trades were treated together because, although the men's occupational exposures differed, they had similar prevalences of respiratory symptoms and similar changes in lung function. ${ }^{7810}$ "Shipyard" (SY) was used to identify men who either continued to work in one of the original shipyards or had left but had practised their trade in another shipyard for at least $85 \%$ of the available time; hence WCB.SY identified welders and caulker/burners who continued in their trade throughout the period of follow up.

Smokers (Sm) were defined as current smokers plus those who had discontinued smoking within the preceding six months, nonsmokers (Non-sm) as those who had never smoked as much as one cigarette per day for as long as one year, and the remainder were ex-smokers (Ex-sm). Changes over the period of follow up were expressed as absolute change (e.g. BMdiff), annual rate of change (e.g. $\triangle \mathrm{BMI}$ ), and percentage change.

Analysis of changes in body mass was based on all subjects, but that of $\mathrm{FEV}_{1}$ was confined to smokers and non-smokers since a decision to discontinue smoking might have been influenced by other related variables including deterioration in lung function or loss of income following leaving the shipyard. Cross-sectional analysis with respect to age was limited to men aged 25 years and older because before this age the men were still growing, ${ }^{5}$ whilst the effects of discontinuing smoking were analysed for men who were smokers at the initial assessment.

In the multiple regression analyses terms were admitted in a stepwise fashion in the order which reflected their contributions to the explained variance. A 5\% level of probability was accepted as significant. Reference values were those previously found appropriate for UK populations. ${ }^{5}$ The peak age was that at which the annual change in lung function was zero, after making allowance for change in stature and other nuisance variables. ${ }^{15}$ The analysis was performed both for the data from yard 2 and for the combined data from the two yards. The two analyses gave effectively the same results.

To explore the effects on lung function of different degrees of change in body mass, independent of age and change in stature, subjects were subdivided by level of change in body mass index $(\triangle \mathrm{BMI})$ into 16 subgroups; the levels were chosen to give approximately equal numbers in each subgroup. The results were adjusted to age 40 years.

\section{Results}

DESCRIPTION OF SUBJECTS

At the initial assessment the mean (SD) age of the 1005 subjects was $36 \cdot 5(12 \cdot 2)$ years, the 


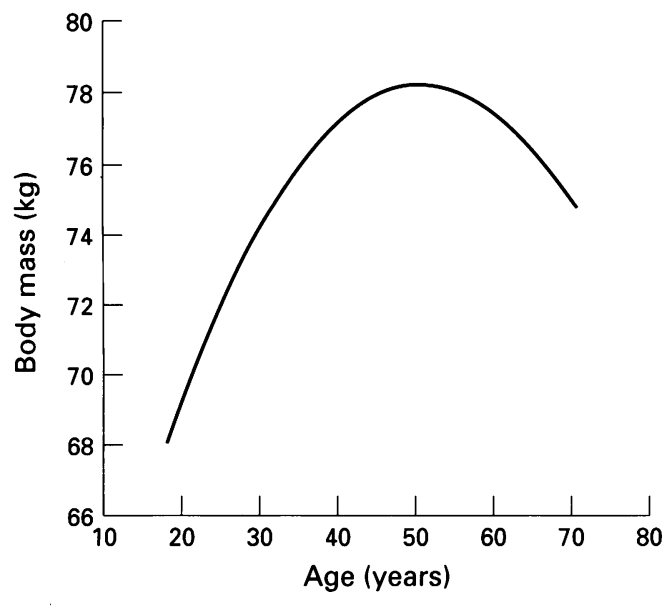

Figure 1 Evolution of body mass in a typical shipyard worker; nuisance variables were allowed for, as in Eqn 1 $(n=1005)$. At any age the mean increase in body mass associated with discontinuing smoking was $3.13 \mathrm{~kg}$.

body mass was $74 \cdot 8(11 \cdot 1) \mathrm{kg}$, and the stature $1.73(0.07) \mathrm{m}$. The mean (SD) annual changes in body mass $(\triangle B M)$ and body mass index $(\triangle \mathrm{BMI})$ were, respectively, $0.26(0.794) \mathrm{kg} /$ year and $0.081(0.264) \mathrm{kg} / \mathrm{m}^{2} /$ year. The mean (SD) increase in stature (Stdiff) was 0.13 $(0.54) \mathrm{cm}$, reflecting growth in men aged 25 years and less.

EVOLUTION OF BODY MASS WITH AGE

Over the period of follow up the body mass of the younger subjects increased whilst that of the older subjects decreased. Using the data for all subjects, change in body mass was related to age during follow up and other variables according to the following relationship (Eqn 1):

BMdiff (mean $1.83 \mathrm{~kg}$ ) $=6.83-0.119$ Age + 3.13 if Ex-sm-0.052 initial level +0.468 interval $+0 \cdot 647 \operatorname{Stdiff}\left(R^{2}=0 \cdot 14 ; \mathrm{RSD}=5 \cdot 04\right)$.

The evolution of body mass with age in a smoker or non-smoker of $1.76 \mathrm{~m}$ in height and initial body mass of $68 \mathrm{~kg}$ at the age of 18 is shown in fig 1 . The evolution of body mass index was similar.

On average, $78 \%$ of the changes in body mass $(\triangle \mathrm{BM}$ or $\Delta \mathrm{BMI})$ with age were due to changes in body fat ( $\Delta \%$ fat, calculated from skinfold thickness) which accounted for ap-

Table 1 Change in lung function per kg change in body mass after allowance for nuisance variables in shipyard workers of initial age $>25$ years $(n=772)$

\begin{tabular}{|c|c|c|c|c|}
\hline & \multirow[t]{2}{*}{ Mean change } & \multirow{2}{*}{$\begin{array}{l}\text { Mean (SE) } \\
\text { change per kg }\end{array}$} & \multicolumn{2}{|c|}{ Variance explained (\%) } \\
\hline & & & By BMdiff & Total \\
\hline $\begin{array}{l}\text { FEV }_{1} \text { diff }(\mathrm{ml}) \\
\text { FVCdiff }(\mathrm{ml})\end{array}$ & $\begin{array}{l}-220 \cdot 2 \\
-124 \cdot 0\end{array}$ & $\begin{array}{l}-17 \cdot 6(2 \cdot 0) \\
-21 \cdot 1(2 \cdot 5)\end{array}$ & $\begin{array}{l}6 \cdot 9 \\
5 \cdot 7\end{array}$ & $\begin{array}{l}19 \cdot 3 \\
17 \cdot 3\end{array}$ \\
\hline
\end{tabular}

$\mathrm{FEV}_{1}=$ forced expiratory volume in one second; $\mathrm{FVC}=$ forced ventilatory capacity; $\mathrm{BM}=$ body mass.

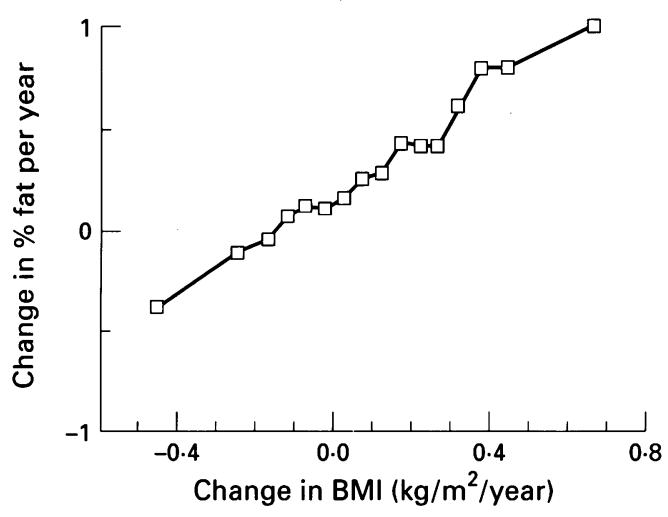

Figure 2 Grouped data showing the average relationship of change in percentage fat to extent of change in body mass index (BMI).

proximately $50 \%$ of the variance (fig 2 ). Of the individual skinfolds, the change in thickness below the subscapula contributed most (approximately two thirds), with the change in thickness over the triceps muscle accounting for most of the remainder.

CHANGE IN BODY MASS AND LUNG FUNCTION Absolute changes in $\mathrm{FEV}_{1}$ and FVC over the period of follow up ( $\mathrm{FEV}_{1}$ diff and FVCdiff) were negatively correlated with absolute changes in body mass (BMdiff or BMIdiff), and the associations persisted after making allowance for age, any change in smoking habit, occupational exposure, initial level of lung function or, in the case of $\mathrm{FEV}_{1}$, the interval between measurements. The interaction term Age-BMIdiff did not make a significant contribution. The effects on lung function of a $1 \mathrm{~kg}$ change in body mass - that is, the partial regression coefficient of change in lung function (for example, $\mathrm{FEV}_{1}$ diff) on change in body mass (BMdiff) - after allowing for the nuisance variables are given in table 1 .

The relationships were independent of the extent of the change in body mass, including whether it was positive or negative, except in the group of men who had lost the most weight (fig 3). Amongst this group the increase in

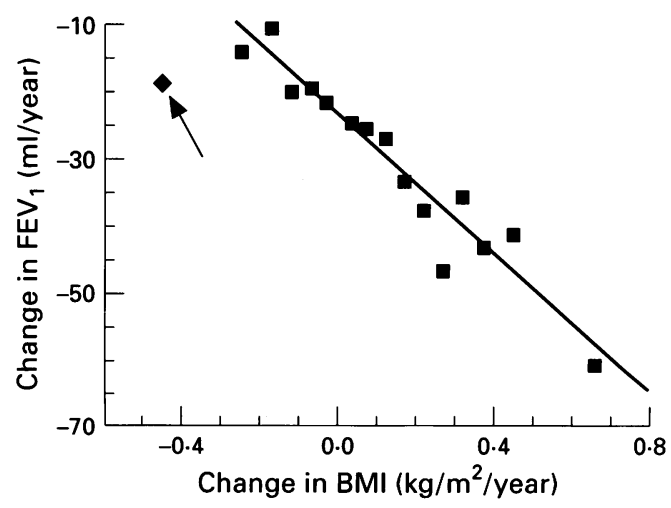

Figure 3 Grouped data for men with a mean age of at least 25 years, showing the average relationship of annual change in $F E V_{1}(\triangle F E V)$ to extent of annual change in change in $F E V_{1}\left(\triangle F E V_{\mathcal{L}}\right.$ to extent of annual change in
body mass index $(\triangle B M I)$. $\triangle F E V_{1}$ was standardised to age 40 years. The regression line was fitted to all points except that for subjects who lost the most weight ( $\triangle B M I$ less than $-0.3 \mathrm{~kg} / \mathrm{m}^{2} /$ year). The aberrant point is indicated by an arrow. 
Table 2 Multiple regression equations describing changes in $F E V_{1}$ and $F V C\left(\triangle F E V_{1}\right.$ and $\left.\triangle F V C\right)$ in shipyard workers (Smokers (Sm) and non-smokers (Non-sm), $n=885$ ) showing how estimates of the effects of continuing to weld (WCB.SY) and of peak age are influenced by including changes in body mass index ( $\triangle B M I)$ amongst the reference variables

\begin{tabular}{|c|c|c|c|c|}
\hline \multirow{4}{*}{ Constant terms } & \multicolumn{2}{|c|}{$\triangle F E V_{1}(-24 \cdot 8 \mathrm{ml} /$ year $)$} & \multicolumn{2}{|c|}{$\triangle F V C(-7.13 \mathrm{ml} /$ year $)$} \\
\hline & $\triangle B M I$ ignored & $\triangle B M I$ allowed for & $\triangle B M I$ ignored & $\triangle B M I$ allowed for \\
\hline & $51 \cdot 3 \quad(13.4)$ & $58 \cdot 4 \quad(12 \cdot 9)$ & $93 \cdot 3 \quad(16 \cdot 3)$ & $104 \cdot 7 \quad(16 \cdot 0)$ \\
\hline & & & & \\
\hline Mean age $(39.6$ years $)$ & $-1 \cdot 00(0 \cdot 16)$ & $-1 \cdot 30(0 \cdot 16) \dagger$ & $-1 \cdot 51(0 \cdot 18)$ & $-1 \cdot 74(0 \cdot 18)$ \\
\hline$\Delta \mathrm{BMI}\left(\right.$ mean $0.065 \mathrm{~kg} / \mathrm{m}^{2} /$ year $)$ & Omitted & $-40.9(5.07)$ & Omitted & $-38.9(6.31)$ \\
\hline Age.Sm (mean 18.7 years) & $-0.44(0.063)$ & $-0.46(0.061)$ & $-0.37(0.078)$ & $-0.38(0.076)$ \\
\hline WCB (mean 0.708$)$ & $-7.98(2.92)$ & NS & $-7.93(3.60)$ & $-7 \cdot 38(3.53)$ \\
\hline WCB.SY (mean $0 \cdot 181)$ & NS & $-8.21(3.31)$ & NS & NS \\
\hline Initial levels (mean 3.78 and 4.941 ) & $-6 \cdot 15(2 \cdot 11)$ & $-5 \cdot 18(2 \cdot 04)$ & $-5.96(2 \cdot 26)$ & $-5 \cdot 86(2 \cdot 21)$ \\
\hline$\underset{R^{2}}{\text { Stdiff }(\text { mean } 0.133 \mathrm{~cm})}$ & $6.02(2.52)$ & $5.06(2.44)$ & $9.03(3.11)$ & $8 \cdot 16(3.04)$ \\
\hline 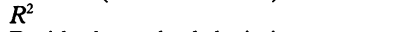 & $0 \cdot 16$ & $0 \cdot 22$ & $0 \cdot 19$ & 0.22 \\
\hline Residual standard deviation & $38 \cdot 4$ & $37 \cdot 2$ & $47 \cdot 4$ & $46 \cdot 4$ \\
\hline Peak age at constant stature (years) & & & & \\
\hline Non-smoker, non-welder & $28 \cdot 0$ & $29 \cdot 9+t$ & $42 \cdot 3$ & $43 \cdot 5 \mathrm{tt}$ \\
\hline Smoker, non-welder & $19 \cdot 8$ & $23 \cdot 2+t$ & $37 \cdot 7$ & $39 \cdot 4+t$ \\
\hline
\end{tabular}

$\dagger$ Decrease compared with previous coefficient, $\mathrm{p}<0.05$.

†† At constant BMI.

WCB = welder or caulker/burner; $S Y=$ current shipyard worker; Stdiff = change in stature

Values in parentheses are standard errors.

$\triangle \mathrm{FEV}_{1}$ was apparently less than might have been expected from the other results. The aberrant group was not exceptional with respect to age which was negatively correlated with $\triangle \mathrm{BMI}$ over the whole range of groups, to level of $\mathrm{FEV}_{1}$ which was close to the reference value for all groups, or to the proportion of men with regular wheeze. The proportion with chronic cough and phlegm was somewhat above average, but the difference was not significant.

EFFECTS OF DISCONTINUING SMOKING

Of 522 men who were smokers at the first assessment, 120 discontinued smoking so were ex-smokers at follow up. For these men, after adjusting for mean age, initial level of body mass, and change in stature, discontinuing smoking was associated with a mean (SE) increase in body mass of $3.37(0.54) \mathrm{kg}$. There were associated significant increases in the subscapular and triceps skinfold thicknesses, but not in the biceps or suprailiac measurements.

In the same group of subjects the change in $\mathrm{FEV}_{1}\left(\mathrm{FEV}_{1}\right.$ diff) was related to the mean age and the interval between measurements, but terms for change in stature, initial $\mathrm{FEV}_{1}$, shipyard trade, and continuing to work in the shipyard were not significant. The term for exsmoking was significant only after allowance had been made for change in body mass; exsmoking was then associated with a mean increase in $\mathrm{FEV}_{1}$ of $62.9(29.6) \mathrm{ml}$. Discontinuing smoking did not improve the FVC.

CONTRIBUTIONS OF CHANGES IN

ANTHROPOMETRIC VARIABLES TO EVOLUTION OF LUNG FUNCTION

This aspect was investigated using as subjects all 885 men who did not change their smoking habits during the period of follow up. The changes in lung function were analysed with respect to age, absolute change in stature (Stdiff), smoking, shipyard trade, and working in or having left the shipyard (SY). The contribution of $\triangle \mathrm{BMI}$ was then assessed. The results for $\triangle F E V_{1}$ and $\triangle F V C$ are summarised in table 2 .
Variance explained by the regressions

In the absence of allowance for $\triangle B M I$, the proportion of the variance in $\triangle F E V_{1}$ which was explained by the regression $\left(R^{2}\right)$ was $0 \cdot 16$ $(16 \%)$. This was increased by 0.06 to 0.22 by the inclusion of $\triangle B M I$ as an additional reference variable. The corresponding increase for $\triangle F V C$ was $0: 04$. Substituting for $\triangle B M I$ the changes in the subdivisions of body mass index, fat free mass index, and percentage body fat did not further improve the variance explained by the regressions.

\section{Peak age}

In non-smokers who were not welders or caulker/burners, the peak ages at constant stature $($ Stdiff $=0)$ for $\mathrm{FEV}_{1}$ and FVC unstandardised for $\triangle \mathrm{BMI}$ were, respectively, 28.0 and 42.3 years. The peak ages were reduced by smoking. Irrespective of smoking habit, standardisation to constant BMI increased the peak ages (table 2); in addition, the peak levels of lung function were increased. The changes in $\mathrm{FEV}_{1}$ are illustrated in fig 4.

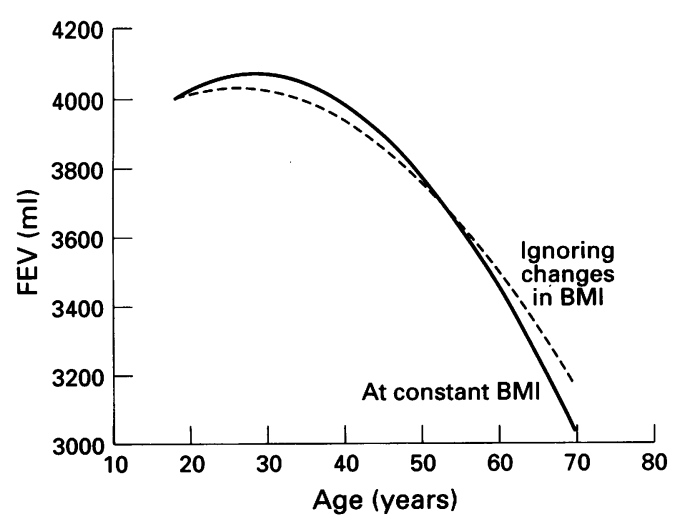

Figure 4 Evolution of $F E V_{1}$ in a typical non-smoking non-welder with an $F E V_{1}$ at age 18 years of $4 \cdot 0$ litres with and without allowance for coexisting changes in body mass. 


\section{Effect of shipyard trade}

In the absence of an allowance for change in body mass, the $\triangle \mathrm{FEV}_{1}$ was related to age, smoking, initial $\mathrm{FEV}_{1}$, change in stature during follow up, and work as a welder or caulker/ burner. Discontinuing work as a welder or caulker/burner apparently did not have a beneficial effect - that is, the term WCB.SY did not make a significant contribution. However, on discontinuing welding the body mass increased $(p=0.05)$ and, when this was allowed for by inclusion of $\triangle \mathrm{BMI}$ amongst the reference variables, an amelioration of the decline in $\mathrm{FEV}_{1}$ became apparent.

\section{Discussion}

In this longitudinal study we have shown a significant effect of change in body mass on the level of FEV 1 and FVC. Body mass is the sum of its constituents, which include body muscle and fat. The muscle component can influence the maximal respiratory pressures and, hence, inspiratory capacity, indices of which inspiratory capacity forms a part, and peak expiratory flow. ${ }^{1617}$ The fat component can influence the total lung capacity and its subdivisions, the work of breathing and, in some circumstances, the airway calibre. ${ }^{5}$ In cross-sectional studies an atypical body mass can reflect an excess or diminution in either fat or muscle, or both. The effects of these variables on lung function have opposite signs, hence they tend to cancel out. As a result, the overall contribution of body mass to crosssectional descriptions of ventilatory capacity is relatively small. In longitudinal studies, whether or not changes in total muscle or fat affect the lung function depends critically on where the changes occur. Hypertrophy of muscles acting on the shoulder girdle can assist inspiration, whilst that of muscles acting on the lower limbs cannot. Similarly, fat which is deposited centrally in the thorax or abdomen could displace air from the lungs, whilst that on the buttocks and thighs cannot. Among the subjects included in this study, on average $78 \%$ of the increase in body mass represented accumulation of fat. The relevant sites were thoracic (subscapular) rather than lower abdominal (suprailiac), but no direct measurements were made of intrathoracic and upper abdominal compartments.

Men tend to deposit fat centrally, whilst in women the deposition is often peripheral. ${ }^{1819}$ The effects on the lungs of an increase in body mass due to fat should therefore be greater in men than in women, and this has been observed to be the case. ${ }^{3}$ Causality could imply that the changes were reversible but only if, in any individual, the sites of deposition and removal were the same.

Reversibility was a feature of the previous study by one of the present authors. ${ }^{1}$ In the present study the relationship between change in $\mathrm{FEV}_{1}$ and change in body mass standardised for stature applied to most of those subjects in whom body mass decreased during follow up, as well as to those in whom the mass increased (fig 3). By contrast, a U-shaped relationship between the level of body mass and $\mathrm{FEV}_{1}$ was observed by Dockery and colleagues, ${ }^{20}$ with subjects who were materially overweight or underweight having the lower values. However, these results did not relate to changes in body mass.

The present effect of body mass was independent of age. In this the result resembled that of Chen et al in a sample from a whole population, ${ }^{3}$ but differed from those of Bande and colleagues who studied air crew, ${ }^{2}$ and of Borkan et al who investigated patients with ischaemic heart disease; ${ }^{21}$ the reason for the difference is unclear. The present levels of the changes in $\mathrm{FEV}_{1}$ and $\mathrm{FVC}$ of $17.6(2.0) \mathrm{ml} / \mathrm{kg}$ and $21.1(2.5) \mathrm{ml} / \mathrm{kg}$ were similar both to the previous results ${ }^{1}$ and to those of Chen. ${ }^{3}$ Thus, the existence of an effect is not in doubt. The present findings suggest that it is due to changes in body fat ( $\Delta \% \mathrm{Fat})$; however, for this index the measurement error is large and, probably on this account, the use of $\Delta \%$ Fat did not contribute more to the variance in $\triangle \mathrm{FEV}_{1}$ and related indices than $\triangle \mathrm{BMI}$ itself.

The average effect on $\mathrm{FEV}_{1}$ of a $1 \mathrm{~kg}$ change in body mass $(17.6 \mathrm{ml})$ is of similar magnitude to the average annual change in $\mathrm{FEV}_{1}$ (15-20 ml/year depending on age and smoking habit). Hence, a factor which is associated with a change in body mass will affect the evolution of lung function independent of any direct action of that factor upon the lungs. Among working populations the process of ageing, giving up smoking, and ceasing to engage in physically demanding work could fall into this category. Among patients a similar effect might be expected if the disease process, or resulting treatment, led to a change in body mass. Loss of body mass is a feature of many chronic respiratory disorders, whilst an increase can occur as a result of antitubercular or steroid therapy, or lung transplantation. The changes in body mass associated with all these situations are likely to affect the lung function.

This analysis was based on data from a series of studies, funded by a number of organisations, and reflecting hard work by many individuals; all their contributions are acknowledged in the associated reports. ${ }^{7-10}$ Facilities for the analysis were provided associated reports.
by the University of Newcastle upon Tyne, including Visitor status for JEC, and we are indebted to Professor A Allen of the Department of Physiological Sciences for his support. Mr R Scott and Mr E Thomson (Department of Medical Physics) helped with some computing and Dr T J Cole (MRC Dunne Nutrition Laboratory, Cambridge) provided some references. DJC is also indebted to Dr P M Tweeddale and the University of Edinburgh for additional help.

1 Cotes JE, Gilson JC. Effect of inactivity, weight gain and antitubercular chemotherapy upon lung function in working coal-miners. Ann Occup Hyg 1967;10:327-35.

2 Bande J, Clement J, Van de Woestijne KP. The influence of smoking habits and body weight on vital capacity and FEV in male airforce personnel: a longitudinal and crossFEV ${ }_{1}$ in male airforce personnel: a longitudinal and cross-

3 Chen Y, Horne SL, Dosman JA. Body weight and weight gain related to pulmonary function decline in adults: a six year follow up study. Thorax 1993;48:375-80.

4 Rolland-Cachera MF, Cole TJ, Sempe M, Tichet J, Rossignol NC, Charraud A. Body mass index variations - centiles from birth to 87 years. Eur $\mathcal{f}$ Clin Nutr 1991;45:13-21.

5 Cotes JE. Lung function: assessment and application in medicine. 5th edn. Oxford: Blackwell Scientific Publications, 1993.

6 Quanjer PhH, Tammeling GJ, Cotes JE, Pedersen OF, Peslin R, Yernault J-C. Standardized lung function testing: Peslin R, Yernault J-C. Standardized lung function testing: lung volumes and forced ventilatory

7 Cotes JE, Feinmann EL, Male VJ, Rennie FS, Whickham CAC. Respiratory symptoms and impairment in shipyard welders and caulker/burners. Br F Ind Med 1989;46:292301 
8 Chinn DJ, Stevenson IC, Cotes JE. Longitudinal respiratory survey of shipyard workers: effects of trade and atopic status. Br F Ind Med 1990;47:83-90.

9 Weller JJ, El-Gamal FM, Parker L, Reed JW, Cotes JE. Indirect estimation of maximal oxygen uptake for study of working populations. Br F Ind Med 1988;45:532-7.

10 Chinn DJ, Cotes JE, El-Gamal FM, Wollaston JF Respiratory health of young shipyard welders and other tradesmen studied cross-sectionally and longitudinally. Occup Environ Med 1995;55:33-42.

11 Medical Research Council. Questionnaire of respiratory symptoms. London: Medical Research Council, 1976

12 Weiner JS, Lourie JA, eds. Practical human biology. London: Academic Press, 1981.

13 Durnin JVGA, Womersley J. Body fat assessed from total body density and its estimation from skinfold thickness: measurements on 481 men and women aged from 16 to measurements on 481 men and wo

14 McDermott M, McDermott TJ. Digital incremental techniques applied to spirometry. Proc $R$ Soc Med 1977;70: $169-71$.

15 Burrows B, Lebowitz MD, Camilli AE, Knudson RJ. Longitudinal changes in forced expiratory volume in on second in adults. Methodologic considerations and find- ings in healthy nonsmokers. Am Rev Respir Dis 1986;133: 974-80

16 Cotes JE, Dabbs JM, Hall AM, Heywood C, Laurence KM Sitting height, fat free mass and body fat as reference variables for lung function in healthy British children: comparison with stature. Ann Hum Biol 1979;6:307-14.

17 Schoenberg JB, Beck GJ, Bouhoys A Growth and decay of pulmonary function in healthy blacks and whites. Respir Physiol 1978;33:367-93.

18 Krotkiewsli M, Bjorntorp P, Sjostrom L, Smith U. Impact of obesity on metabolism in men and women: importance of regional adipose tissue distribution. 7 Clin Invest 1983 ; 72:1150-62

19 Ashwell M, Cole TJ, Dixon AK. Obesity: new insight into the anthropometric classification of fat distribution shown by computed tomography. BMF 1985;290:1692-4.

20 Dockery DW, Ware JH, Ferris BG Jr, Glicksberg DS, Fay ME, Spiro A III, et al. Distribution of forced expiratory volume in one second and forced vital capacity in healthy, white, adult never-smokers in six US cities. Am Rev Respir Dis 1985;131:511-20.

21 Borkan GA, Sparrow D, Wisniewski C, Vokonas PS. Body weight and coronary disease risk: patterns of risk factor Normative aging study. Am f Epidemiol 1986;124:410-19. 